\title{
Diagnosis and Arthroscopic Treatment of Synovial Chondromatosis of Glenohumeral Joint: A Case Report
}

\author{
Fayaz Memon ${ }^{1}$, Eknath D Pawar ${ }^{1}$, Devanshu Gupta ${ }^{1}$, Amit Kumar Yadav ${ }^{1}$
}

Learning Point of the Article:

A synovial chondromatosis of shoulder can be successfully treated with arthroscopic excision, no matter how much is the number of loose bodies.

\section{Abstract}

Introduction: Synovial chondromatosis is a rare benign entity with the presence of cartilaginous or osseous loose bodies in the synovium. It commonly involves the larger joints such as the knee, hip, ankle and rarely the shoulder joint manifesting with pain, swelling, and restriction of movements. The treatment of choice is surgical intervention in symptomatic patients using either the open or the arthroscopic approach.

Case Report: Here, we report a rare case of synovial chondromatosis affecting the right shoulder joint in a 23-year-old male with a 5-year disease duration who presented with progressive pain and restriction in movements which were impacting his routine activities. The loose bodies were removed using the arthroscopic approach combined with a partial synovectomy, and intra-articular methylprednisolone post procedure. The patient showed an excellent recovery in joint mobility within 4 weeks post-operatively, and there were no clinical signs of recurrence during a 6 month follow-up period.

Conclusion: We believe that arthroscopic surgery is effective in the treatment of patients with synovial chondromatosis with advantages such as good visualization, lesser morbidity, and early return of functional activities.

Keywords: Synovial chondromatosis, loose bodies, arthroscopy.

\section{Introduction}

Synovial chondromatosis is a rare, benign disorder of synovial joints, tendons, and bursae. It has been reported to involve the knee, hip, elbow, wrist, ankle frequently, and shoulder being a rare site $[1]$. The etiology is unknown but suggested that pathogenesis involves foci of synovial chondroid metaplasia that become pedunculated and eventually break free and become loose bodies within the joint. Secondary causes include trauma, osteochondritis dissecans, and rheumatoid arthritis. The resulting loose bodies can undergo further endochondral ossification and may cause erosive damage to the articular surfaces. The process runs in three stages: (a) Active intrasynovial disease without loose bodies, (b) transitional lesions with synovial proliferation and free loose bodies, and (c) loose bodies without the synovial disease [2]. Conventionally, the treatment of synovial chondromatosis was open arthrotomy with subtotal synovectomy and removal of loose bodies. The current recent advances in arthroscopy techniques have provided excellent visualization of the joints with significantly less morbidity and earlier post-operative rehabilitation than open arthrotomy.

\section{Case Report}

A 23-year-old right-hand dominant male presented with 5-year history of the right shoulder pain and restriction of movements, which was insidious in onset and gradually progressive, the restriction worsened over period of time. He was a volleyball player and since the past 2 years, he could not play, and his activities of daily living were restricted. There was no history of trauma or any comorbidities. Physical examination revealed
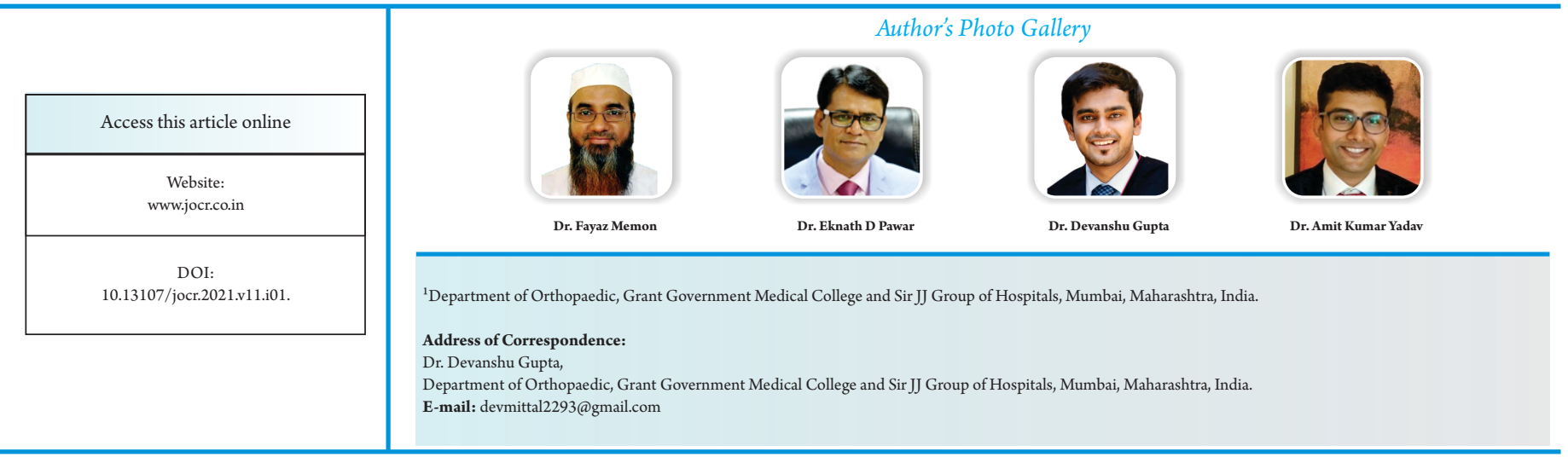
Author's Photo Gallery

Journal of Orthopaedic Case Reports | pISSN 2250-0685 | eISSN 2321-3817 | Available on www.jocr.co.in | doi:10.13107/jocr.2021.v11.i01. This is an Open Access article distributed under the terms of the Creative Commons Attribution Non-Commercial License (http://creativecommons.org/licenses/by-nc/3.0) which permits unrestricted non-commercial use, distribution, and reproduction in any medium, provided the original work is properly cited. 


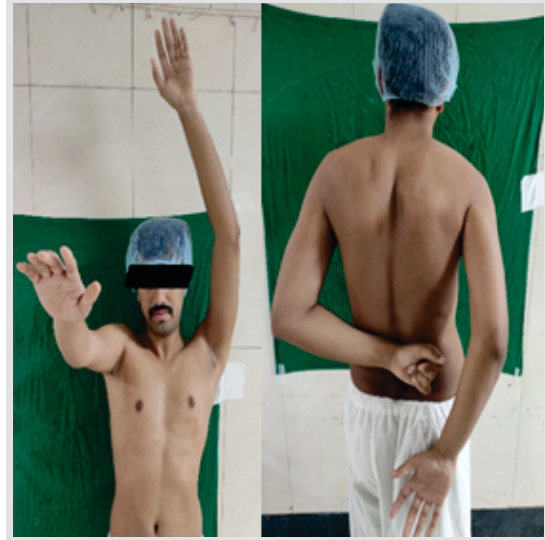

Figure 1: Significant restriction in forward flexion and internal rotation at the right shoulder joint on presentation.

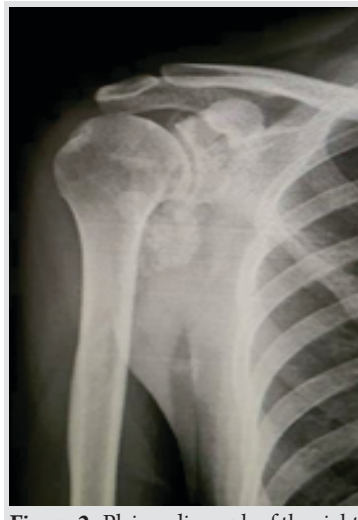

Figure 2: Plain radiograph of the righ shoulder joint showing multiple well defined calcific foci with centra lucency.

stiffness and crepitus over the right shoulder joint with severe restriction of abduction, forward flexion, and internal rotation (Fig. 1).

Plain radiographs (Fig. 2) and computed tomography (including three dimensional reconstruction images) (Fig. 3) revealed multiple well-defined calcified foci with central lucency engulfing glenohumeral joint (intra- and extraarticular) anteriorly, posteriorly, superiorly, and inferiorly including biceps tendon consistent with synovial chondromatosis. Magnetic resonance imaging done suggested moderate synovial effusion with synovial thickening and early degenerative changes with loose bodies which were consistent with the findings on computed tomography (Fig.4).

Standard arthroscopy was performed under interscalene block and general anesthesia in lateral position with posterior portals along with anteroinferior and anterosuperior portals. Active, intrasynovial proliferation was noted with intra-articular and extra-articular loose bodies (Fig. 5). With motorized shaver, partial synovectomy was performed using anterosuperior and anteroinferior portals and by inter-changing the portals frequently, the osteochondral loose bodies were removed with larger arthroscopic grasper (Fig. 5). Approximately 20



Figure 3: Three-dimensional computed tomography was also consistent with synovial chondromatosis.

fragments, ranging in size from 0.3 to $3.5 \mathrm{~cm}$, were removed (Fig. 6) over a duration of $1 \mathrm{~h}$.

The histopathological examination of the loose bodies and synovial tissue confirmed the presence of cartilaginous synovial metaplasia consistent with synovial chondromatosis (Fig. 7). The loose bodies were composed of cartilage in various stages of calcification and endochondral ossification. Post-operative plain radiograph was done (Fig. 8). The patient immediately began pendular exercise followed by passive and active-assisted shoulder range of movement exercises. There was a dramatic improvement in the range of movement in the immediate postoperative period (Table 1). By 4 weeks post-operatively, the patient could return to work (Fig. 9).

\section{Discussion}

Synovial chondromatosis, previously known as synovial osteochondromatosis, synovial chondrometaplasia, articular ecchondrosis, and synovial chondrosis, has an incidence of 1 in 100,000 [3]. It is a benign process characterized by the presence of multiple round cartilaginous nodules or osseous loose bodies within the synovium. It usually involves the larger joints, most frequently the hip and knee joint. Rarely, it may involve extra-

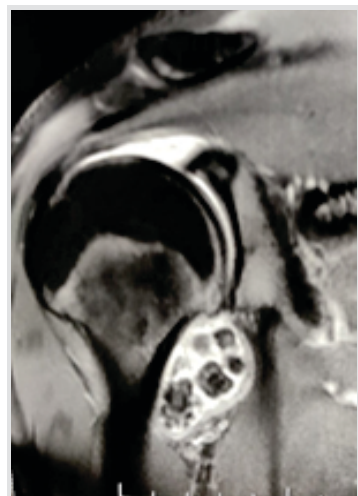

Figure 4: Magnetic resonanceimaging showed multiple lobulated, osseocartilagenous loose bodies with moderate synovial effusion.

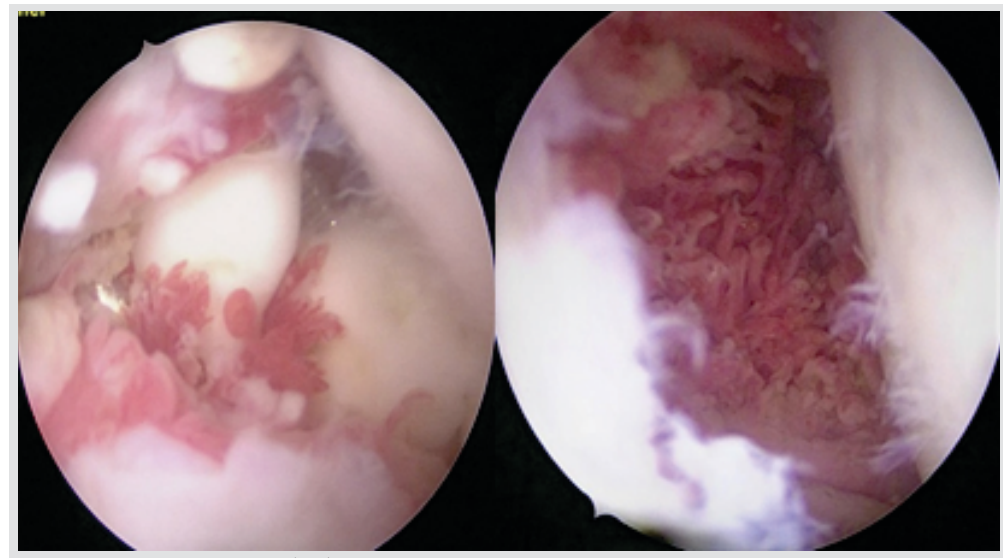

Figure 5: Arthroscopic view (left) showing osteochondral loose bodies between glenoid and humeral head and post-excision empty axillary region of glenohumeral joint (right).

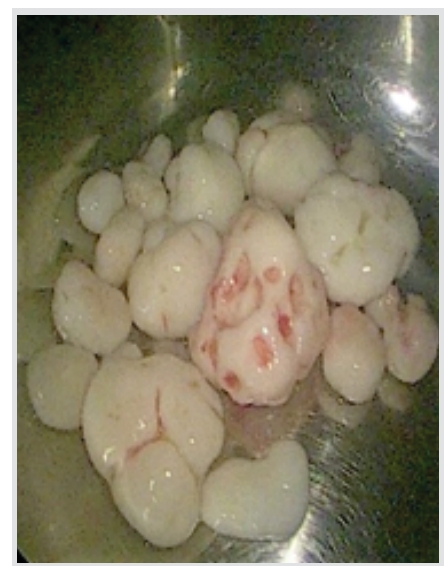

Figure 6: Excised loose bodies measuring $0.3-3.5 \mathrm{~cm}$ in size. 


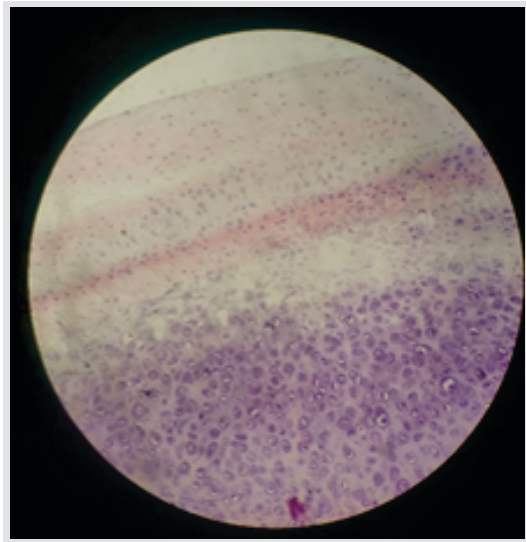

Figure 7: Clusters of chondrocytes showing binucleation on histopathology

articular sites, arising in synovium

about the tendons or bursa [4].

The primary form of synovial chondromatosis has an incidence of $1: 100,000$ and typically affects patients in the third to fifth decades of life, with a male predominance. The etiology of primary synovial chondromatosis is unknown, although cytogenetic finding strongly suggests that it is a clonal proliferation. Trauma has been postulated as a possible stimulus of metaplasia of the synovial cells into chondrocytosis [5].

Milgram described three stages in primary synovial chondromatosis:

- Stage 1: The chondromas are attached to the synovium;

- Stage 2: The chondromas breach the synovium and are released as free bodies into the joint capsule;

- Stage 3: The synovial disease becomes inactive, but the intraarticular nodules remain.

Studies indicate that there is no correlation between these stages and the duration of clinical symptoms or patient's age. It is also not mandatory for the primary synovial chondromatosis to progress through these stages in the same order [1]. Secondary reasons include trauma, osteochondritis dissecans, rheumatoid arthritis, and tubercular arthritis [6].

The clinical diagnosis of synovial chondromatosis may be difficult as the clinical history and physical examination are non-specific. The patients most often complain of pain, swelling, and restricted range of motion of the affected joint which is insidious in onset and gradually progressive, with an average of 5 years duration before diagnosis. The incidence of synovial chondromatosis is 1 in 100,000 . The knee (50-65\%)

\begin{tabular}{|c|c|c|c|c|}
\hline \multicolumn{5}{|c|}{ Table 1: Shoulder range of motion - pre-operative and post-operatively } \\
\hline Movement at shoulder joint & $\begin{array}{c}\text { Normal range of } \\
\text { motion (in degrees) }\end{array}$ & $\begin{array}{c}\text { Pre- } \\
\text { operative }\end{array}$ & $\begin{array}{c}\text { Post-operative } \\
\text { (day 1) }\end{array}$ & $\begin{array}{c}\text { Post- operative } \\
\text { (6 month) }\end{array}$ \\
\hline Forward flexion & $0-180$ & 100 & 160 & 170 \\
\hline Extension & $0-50$ & 50 & 50 & 50 \\
\hline Internal rotation & $0-90$ & 25 & 70 & 80 \\
\hline External rotation & $0-90$ & 20 & 60 & 80 \\
\hline Abduction & $0-180$ & 90 & 150 & 170 \\
\hline
\end{tabular}

most commonly affected followed by hip, elbow, wrist, ankle, and shoulder in decreasing frequency [1]. Other less commonly affected joints are the metacarpophalangeal, interphalangeal, distal radioulnar, acromioclavicular, temporomandibular, proximal tibiofibular, and apophyseal articulations [7].

This case of synovial chondromatosis involving the shoulder joint is presented as it is a rare entity. Our patient also presented with mild pain and major restricted range of movements at the right shoulder (patient's dominant side) which had been progressive over the past 5 years. Physical examination revealed stiffness and crepitus with restriction of abduction, internal rotation, and flexion. Plain radiographs and computed tomography showed multiple well-defined calcified foci with central lucency engulfing glenohumeral joint including biceps tendon consistent with synovial chondromatosis.

The treatment of choice is surgical intervention in symptomatic patients with either open or arthroscopic removal of the loose bodies combined with a partial or complete synovectomy. Open technique requires a subscapular tenotomy to reach the joint, which is associated with bigger exposure, more blood loss, insufficient repair of tendon, longer healing time, and delayed rehabilitation [8]. In our case, standard arthroscopic removal of the fragments was performed under block and general anesthesia followed by partial synovectomy. Approximately 20 such fragments, ranging from 0.3 to 3.5 centimeters in size, were removed. Technical difficulties were experienced during the removal of free fragments from the portals. This was due to the large size of the loose bodies which made it difficult to be removed even with the help of the largest arthroscopic grasper. Hence, such big fragments were removed using straight artery forceps. Post-operatively, the patient immediately began pendular exercise followed by passive and active-assisted shoulder range of movement exercises, and by 4 weeks postoperatively, he could return to work. Although the patient in our study showed excellent post-operative improvement; the major limitation is that the follow-up period is short (6 months), and the results may deteriorate with time due to the irreversible 
degenerative changes. Furthermore, a longer follow-up period is necessary to monitor for relapse.

The advantages of the arthroscopic approach include minimal blood loss, lesser morbidity, earlier healing, rehabilitation, and earlier return of functional activities. After the treatment, immediate and durable improvement of the shoulder function can be expected.

Early diagnosis of primary synovial chondromatosis is essential to minimize the chances of permanent degenerative joint disease with proper investigations for its confirmation as the symptoms tend to be non-specific. Arthroscopic excision is an effective treatment of choice with low morbidity and early functional return.

\section{Conclusion}

Synovial chondromatosis of the shoulder joint is a rare disorder.
We believe that arthroscopic surgery is effective in the treatment of patients with synovial chondromatosis. It has advantages such as good visualization, lesser morbidity, and early return of functional activities. However, patients must be counseled about the recurrence and should be followed up regularly.

\section{Clinical Message}

Arthroscopic removal of loose bodies of synovial chondromatosis affecting the shoulder joint, a rare entity in itself, resulted in drastic improvement in the range of movement post-operatively with no evidence of recurrence in the follow-up period.

\section{References}

1. Fowble VA, Levy HJ. Arthroscopic treatment for synovial chondromatosis of the shoulder. Arthroscopy 2003;19:E2.

2. Ranalletta M, Bongiovanni S, Calvo JM, Gallucci G, Maignon G. Arthroscopic treatment of synovial chondromatosis of the shoulder: Report of three patients. J Shoulder Elbow Surg 2009; 18:e4-8.

3. Mo J, Pan J, Liu Y, Feng W, Li B, Luo K, et al. Bilateral synovial chondromatosis of the elbow in an adolescent: A case report and literature review. BMC Musculoskelet Disord 2020;21:377.

4. Calandruccio JH, Jobe M. In: Azar F, Beaty J, Canale ST, editors. Campbell's Operative Orthopaedics. 13th ed. Philadelphia, PA: Elsevier; 2017.p. 3790.
5. Herring J. Tachdjian's Pediatric Orthopaedics. 5th ed. Philadelphia, PA: Saunders/Elsevier; 2014.p. 1123-4.

6. Duymus TM, Yucel B, Mutlu S, Tuna S, Mutlu H, Komur B. Arthroscopic treatment of synovial chondromatosis of the shoulder: A case report. Ann Med Surg (Lond) 2015;4:179-82.

7. Milgram JW. Synovial osteochondromatosis: A histopathological study of thirty cases. J Bone Joint Surg Am 1977;59:792-801.

8. Sood M, Ghai A. Shoulder arthroscopy: Minimally invasive surgery for primary synovial chondromatosis of the shoulder.J Orthop Traumatol Rehabil 2017;9:131-3.
Conflict of Interest: Nil

Source of Support: Nil
Consent: The authors confirm that informed consent was obtained from the patient for publication of this case report

\section{How to Cite this Article}

Memon F, Pawar ED, Gupta D, Yadav AK. Diagnosis and Arthroscopic Treatment of Synovial Chondromatosis of Glenohumeral Joint: A Case Report. Journal of Orthopaedic Case Reports 2021 January; 11(1): 59-62. 